\title{
A Bibliometric Analysis of the Evolution of Six Sigma in the Context of Industry 4.0
}

\author{
Anastasia Efimova ${ }^{1, *}$, Petr Bris ${ }^{1}$, Alexander Efimov² \\ ${ }^{1}$ Faculty of Management and Economics, Tomas Bata University \\ Mostni 5139, 760 01, Zlin, Czech Republic \\ E-mail.efimova@utb.cz(correspondingauthor*); bris@utb.cz \\ ${ }^{2}$ Faculty of Applied Informatics, Tomas Bata University \\ Nad Stranemi 4511, 76005 Zlin, Czech Republic \\ E-mail.efimov@utb.cz.
}

cross $^{\text {ref }}$ http://dx.doi.org/10.5755/j01.ee.32.4.28536

\begin{abstract}
Contemporary world with constantly increasing speed of change and rapid development of technologies is challenging companies to accustom to existing complexity. This led to the fact that various methodologies change accordingly. Practitioners and researchers are seeking the ways to ameliorate processes using emerging technologies. One of the methodologies is Six Sigma that has always been connected with technologies necessary for data collection and analysis. The emergence of new technologies might benefit or challenge Six Sigma. In this paper an attempt has been performed to analyze the trends in research output of the conjunction of Industry 4.0 technologies and Six Sigma methodology. This paper is based on the bibliometric analysis. In the process of analysis, it was found that the combination of Six Sigma methodology and Industry 4.0 technology has positive potential, however, not all of the technologies have been analyzed.
\end{abstract}

Keywords: Six Sigma; Industry 4.0; Smart Factory; Simulation; Big Data.

\section{Introduction}

The contemporary situation with the increasing advancement of technologies and ever-growing complexity has led to the change in all industrial companies around the globe. The speed of production is growing while the customer demands are becoming more diverse and personalized. Companies are challenged to respond to the changes quickly in order to be able to participate in the market competition. Considering all these changes, companies today are trying to improve their factories and production systems trying to create a "Smart factory" relevant to Industry 4.0 era.

For the first time, the term Industry 4.0 was introduced in 2011 in Hannover by German Government (Salkin \& Oner \& Ustundag, \& Cevikcan, 2018) as an attempt to describe the change of the technologies and their ability to be interconnected. This became a new milestone in the development of industries. Currently industries are trying to improve their production to make their industrial processes more interconnected, interrelated and smart.

The change in the industrial processes is inextricably connected with the change in the managerial systems and practices, including quality management. One of the methodologies that gained close attention in the end of XX - beginning of the XXI centuries is Six Sigma. This methodology is based on the analysis of current situation and improvement by eliminating variability and wastes in the process. As Six Sigma has always been related to technologies for data collection and analysis, the current situation with technological improvement creates new opportunities and challenges for the methodology.

Diverse methodologies and their connection with Industry 4.0 became popular for analytical and practical research. Although Six Sigma is a methodology that became widespread its relation to Industry 4.0 especially from the theoretical point of view has been hardly analyzed. Nowadays several papers exist considering the analysis of Lean Six Sigma or Lean, however, the analysis of Six Sigma as a separate methodology has not yet been made. Moreover, to the best knowledge of the authors, no research has been done to identify the distribution and contributions of different institutions into the given topic. The novelty of the research is explained by addressing the research gap mentioned above that is to perform the analysis of Six Sigma methodology combined with Industry 4.0 technologies and investigate the research output. The aim of this paper is to investigate the conjunction of Industry 4.0 technologies with Six Sigma methodology in order to identify future research perspectives and provide the researchers and practitioners with information about the framework of the conjunction. In this paper an attempt is made to analyze the influence of Industry 4.0 technologies on Six Sigma methodology and to identify future research directions. This paper is based on the theoretical review and bibliometric analysis of the existing articles connected with Six Sigma and different Industry 4.0 technologies.

In this paper the relevant materials are considered and summarized and a proposal for specialists on the successful implementation of conjunction of Six Sigma and Industry 4.0 technologies is made, including the future research directions. The given approach will help scientists and Six Sigma practitioners to design a production system paradigm based on the conjunction of Six Sigma and Industry 4.0 in order to improve market figures. 


\section{Background}

\section{Six Sigma}

Six Sigma is data-driven methodology to optimize production quality with the aim of variety reduction. Its purpose is to improve financial results by bringing process under statistical control, increasing speed and reducing investments (George, 2003, p. 6). In practice the mean is often measured, however for the customer the mean is not important. At the same time the customer is interested in the quality of the product that he receives. Six Sigma is focused on process improvement so that the quality would be $99.99966 \%$ with the amount of 3.4 defects per million opportunities (Zhevnov, 2013). Six Sigma means six standard deviations as Sigma usually denotes the standard deviation (Sekhar, \& Mahanti, 2006), (McCarthy, \& Stauffer, 2001). Six Sigma was created by Bill Smith in Motorolla company in 1986 and was enhanced by GE which changed Deming's PDCA cycle into DMADV (Polk, 2011).

Six Sigma could be subdivided into 2 methods DMAIC for process improvement and DFSS for innovations and radical changes. DMAIC is a method for incremental change. It consists of five stages that are Define, Measure, Analyze, Improve and Control. Each stage can be associated with corresponding tools SIPOC, Value stream mapping, Pareto analysis, ANOVA, FMEA, Fishbone Diagrams, Design of Experiments etc. The first three stages are greatly connected with the customer requirements (Seifert, 2005) or product characteristics that are critical-toquality (CTQ). At the Define stage the problem is stated, sponsors are identified, the scopes of the project are settled and the metrics are chosen (Ramakrishnan \& Tsai \& Drayer, $\&$ Srihari, 2008). The measure stage is associated with the measurement of factors influencing the CTQ product with the usage of statistical tools. At the analyze stage an attempt is made to explain the connection between the influencing factor and CTQ, thus analyzing the existing situation. This stage may be associated with tools like Scatter plots, ANOVA, Regression Analysis (George, 2002). The following stage is Improve. At this stage changes to the existing process are introduced. The final stage is Control, as in Six Sigma process cannot be left without control.

DFSS is an abbreviation for Design for Six Sigma. DFSS is a method for radical changes and introduction of new processes. It usually deals with the defects at the early stages of production (Ramakrishnan \& Tsai \& Drayer, \& Srihari, 2008). There are several methods accepted in DFSS that may vary depending on the company and/or company strategy: DMADV (Define, Measure, Analyze, Design, Verify), IDOV (Identify, Design, Optimize, Validate), DIDES (Define, Initiate, Design, Execute, Sustain), IIDOV (Invent, Innovate, Develop, Optimize, Verify), CDOV (Concept development, Design Development, Optimization, Verify, certification), DCOV (Define, Characterize, Optimize, Verify), IDEAS (Identify, Design, Evaluate, Assure, Scale-up) (Shahin, 2008). In this paper we will work with DMADV as it is the most accepted and widespread approach. First 3 stages in DMADV correspond to that of DMAIC. The fourth stage is Design - CTQ and VOC are important on this stage. The process of the introduction of a new process or process simulation is made on this stage. The final stage is Verify. At this stage the process is checked for stability and faults.

Six Sigma has a strong classification of managers involved in Six Sigma projects that consist of Yellow Belt, Green Belt, Black Belt and Master Black Belt. Master Black Belts are usually the leaders of the project that are actively involved. They should have a thorough understanding of Six Sigma and be able to define the project and train other Belts (Stankalla \& Chromjakova, \& Koval, 2019). Black belts usually lead important projects - they have experience in successful implementation of Six Sigma projects and extensive training in Six Sigma (Pyzdek, 2003). Green Belts are part-time team members who know and understand both the process of the project and Six Sigma (George, 2002, p. 105). Usually Green Belts also undergo a prior training in Six Sigma (1-2 weeks). Yellow Belts are those who understand Six Sigma and might be partly involved in the process. Other important Six Sigma team members are Sponsors and Champions. Sponsors are the parties that are interested in the project improvement (George, 2002, p. 22). Champions are the most business-oriented team members (Antony \& Gupta \& Sunder M., \& Gijo, 2018).

In 2002 Michal George introduced the term Lean Six Sigma as the combination of two approaches. It inherited the statistical control from Six Sigma as well as Belt System together with the main tools but was enriched with Lean tools (George, 2002, p. xii).

Thus, Six Sigma from its appearance till to date continues to be widespread and improved in different industries (Ahmed \& Page, \& Olsen, 2020), however the developed technologies evoke a need for Six Sigma to be quickly changed correspondingly in order to be able to answer market needs. It was stated by Saidi \& Soulhi (Saidi, $\&$ Soulhi, 2018) that statistical tools used in Six Sigma do not correspond to the requirements of complex systems. In this paper an attempt is made to analyze the combination of Six Sigma and Industry 4.0 technologies in order to better understand the lack and opportunities of the confluence.

\section{Industry 4.0}

Industry 4.0 as a term stays for the fourth industrial revolution (Salkin \& Oner \& Ustundag, \& Cevikcan, 2018). Every industrial revolution brings attempts of improving the existing manufacturing processes to better meet the market requirements (Yeen Gavin Lai \& Hoong Wong \& Halim \& Lu, \& Siang Kang, 2019). Due to the increase in customer specifications towards goods accompanied with the speed of development, there appeared a need to create a production where the actions and information flow would be coordinated and connected (Salkin \& Oner \& Ustundag, \& Cevikcan, 2018). Thus, the concept of Industry 4.0 is inextricably connected with the creation of "smart factory" where the production units could be interconnected, selfcontrolled and flexible (Leyh \& Martin, \& Schaeffer, 2017).

Industry 4.0 is a combination of several technologies that allow the production to improve digital connection at all levels. The main technologies of Industry 4.0 include the following: cyber-physical systems (CPS), Internet of Things (IIoT), Cloud Computing, Big Data and Big Data Analytics, Simulation, Robotics, Additive manufacturing and Networking (Salkin \& Oner \& Ustundag, \& Cevikcan, 
2018). Adaptive robotics deals with adaptive robots that could provide easier production (Salkin \& Oner \& Ustundag, $\&$ Cevikcan, 2018). Big Data is connected with the work with information and ever-growing amount of data and its processing (Salkin \& Oner \& Ustundag, \& Cevikcan, 2018). Simulation allows to create a 3D model of production flow with key parameters (Chromjakova \& Tucek, \& Bobak, 2017) and to test the system before its application. Cyber Physical Systems establish a correlation between the physical world and computation (Salkin \& Oner \& Ustundag, \& Cevikcan, 2018), with the purpose to create agile production (Sony, 2017). Usually the organizations that introduce CyberPhysical systems are called smart factories (Sony, 2017). Industrial Internet of Things allows the real time process to be connected with virtual reality (Chromjakova \& Tucek, \& Bobak, 2017). Cloud systems are used to create flexible data storage that can be used in real time for processing. Additive manufacture enables the production of objects from digital models using varied materials.

Despite all the improvements and advantages associated with Industry 4.0, technological change in industrial processes is connected with challenges. One of these challenges is the creation of proper methodological change corresponding to surrounding in order to provide specialists with reliable tools in process management and improvement.

\section{Methods}

The research topic was developed based on systematic literature review and bibliometric analysis of the combination of Six Sigma methodology with Industry 4.0 technologies.
The findings from two academic databases, namely WoS all databases and SCOPUS, were analyzed in the paper. The literature of the interest included articles published in scientific journals and conference papers as they are usually considered to be the most widespread academic sources of the information. The findings were limited to the results shown in English; thus, it is important to consider that the outcome could not provide full-scale results.

The paper performs a theoretical analysis of the information gathered from both statistical and analytical points of view. The recommendations for the future research based on the performed analysis and application of data gathered in the process of the study are also provided.

For the research in the databases the advanced search used the search stream of ((six AND sigma) OR (6 AND sigma)) AND ((industry AND 4.0) OR (smart AND factory) OR (big AND data) OR (robotics) OR (simulation) OR (internet AND of AND things) OR (cloud AND computing) OR (cyber AND physical) OR (cyber) OR (additive AND manufacturing)) AND NOT ((lean) OR (lean AND six AND sigma)). This resulted in 46 publications in SCOPUS and 35 in WoS all databases. The found papers were analyzed and the relevant to the study were chosen. After that, the analysis and extraction of the relevant data were conducted. The exclusion criteria included: non-English articles, articles that do not have relationship to the topic, non-availability of the full-text articles. Only articles and conference papers were included in the research. The search process can be seen on Figure 1. The bibliometric analysis was performed with the help of VOS software.

76 results found in SCOPUS and WoS databases

Exclusion of duplicates

52 papers after duplicates exclusion

Exclusion of non-relative to the topic

32 papers found relative to the topic

Figure 1. The Search Process and Results

Finally, the data were analyzed from the point of view of the conjunction of Industry 4.0 technologies and Six Sigma methodology for the purpose of designing production system paradigm. Also, the future research topics were proposed based on this research.

\section{Results}

In this paper, the problem was defined via primary literature search, when it was found that on the conjunction of Six Sigma and Industry 4.0 there are not many articles. Despite the growing interest towards both Six Sigma (according to SCOPUS 226 papers in 2002 to 672 in 2020, with the lowest amount of published papers in 2015 - 498) and Industry 4.0 (according to SCOPUS 89 papers in 2011 to 5505 papers in 2020), the number of articles where the conjunction of two notions is analyzed is consistently law 2 to 5 papers a year (Figure 2).

Thus, the problem that was defined for the "scientific project" was "consequences of the confluence of Six Sigma and Industry 4.0 technology", with the purpose of finding future prospective directions for improvement and successful implementation of Six Sigma in the scopes of Industry 4.0 era.

\section{Bibliometric Analysis}

In the work the bibliometric analysis was done in order to better understand the tendencies of Six Sigma. Thus, several indicators were considered. First of all, key aspects such as the amount of articles per year and the amount of published work per author were also considered as this 
information may inspire collaboration and could provide the basic understanding of trend of the chose topic. Then, the number of articles in different journals was analyzed as this could help to identify the direction for researchers. A word cloud was also drawn in order to help to identify the importance of particular word and terms for the methodology. The last part of the bibliometric analysis consisted of the analysis of the citation and their correlation to the published period.

In our case the advanced search of the databases and the following exclusion of the information resulted in 32 papers corresponding to the topic. These 32 papers were further measured for the information about publishing source, year, author and citation. Also, the word cloud with the words most often used in the articles was formed. The bibliometric analysis was performed with the help of VOSviewer software version 1.6.16 (https://www.vosviewer.com/).

As it could be seen in Figure 2, the amount of publications every year is rather small - with 4 publications maximum in the years 2008 and 2020. This might be explained by the complexity of both topics and their individual development. As the suitability of Six Sigma to complex environments is questionable (Palaci-Lopez \& Borras-Ferris \& da Silva de Oliveria, \& Ferrer, 2020), (Saidi, \& Soulhi, 2018), it's usage with Industry 4.0 technologies is limited.

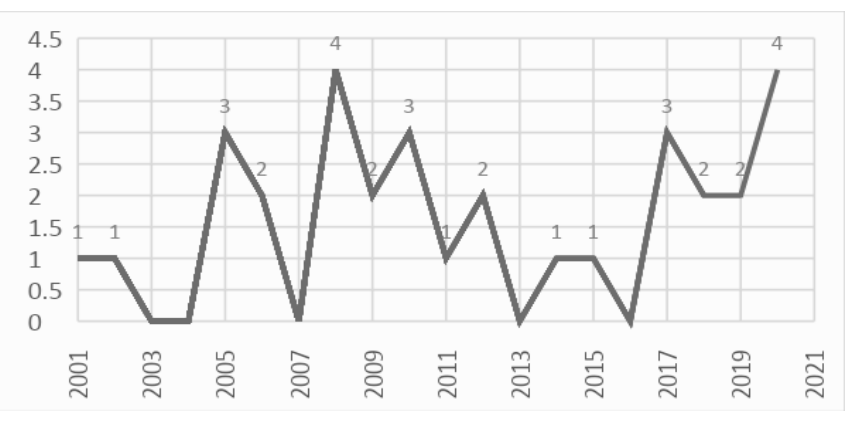

Figure 2. The Amount of Publication in a Year

Next step was identification of the journals and conferences for the publication and the connection between the topic and journals. As Table 1 depicts, there is not a considerable connection of the topic and particular journal, however, some journals have published several articles, with the majority of 2 publications in "International Journal of Lean Six Sigma", "International Journal of Six Sigma and
Competitive Advantage" and "International Journal of Health Care Quality Assurance". As for the conference proceedings there is leading conference where the majority of papers participated in different years with the total amount of 7 publications published in the proceedings "Winter Simulation Conference".

The Amount of Publications per Journal/Conference

\begin{tabular}{|l|l|c|}
\hline & Journal & $\begin{array}{c}\text { Amount of } \\
\text { publication }\end{array}$ \\
\hline 1 & Proceedings - Winter Simulation Conference & 7 \\
\hline 2 & International Journal of Lean Six Sigma & 2 \\
\hline 3 & International Journal of Six Sigma and Competitive Advantage & 2 \\
\hline 4 & International Journal of Health Care Quality Assurance & 2 \\
\hline 5 & Proceedings of the International Conference on Industrial Engineering and Operations Management & 1 \\
\hline 6 & ARPN Journal of Engineering and Applied Sciences & 1 \\
\hline 7 & Journal of Healthcare Engineering & 1 \\
\hline 8 & Operations Research for Health Care & 1 \\
\hline 9 & Journal of Industrial and Production Engineering & 1 \\
\hline 10 & International Journal of Productivity and Performance Management & 1 \\
\hline 11 & SAE Technical Papers & 1 \\
\hline 12 & 2014 International Conference on Information Technology Systems and Innovation, ICITSI 2014 - Proceedings & 1 \\
\hline 13 & International Journal on Interactive Design and Manufacturing & 1 \\
\hline 14 & Quality Engineering & 1 \\
\hline 15 & CSEDU 2010 - 2nd International Conference on Computer Supported Education, Proceedings & 1 \\
\hline 16 & ICST 2010 - 3rd International Conference on Software Testing, Verification and Validation & 1 \\
\hline 17 & International Journal of Six Sigma and Competitive Advantage & 1 \\
\hline 18 & Production Planning and Control & 1 \\
\hline 19 & Proceedings - International Conference on Computer Science and Software Engineering, CSSE 2008 & 1 \\
\hline 20 & Journal of Mechanical Engineering Research and Developments & 1 \\
\hline 21 & Management of Environmental Quality: An International Journal & 1 \\
\hline 22 & Processes & 1 \\
\hline 23 & Managerial Auditing Journal & 1 \\
\hline
\end{tabular}


Then a word cloud summarizing the words that were used in the papers was created. As it could be seen in the word cloud, the most popular words in the articles concerning Six Sigma and Industry 4.0 confluence are Process, Six Sigma, Data, Time, Simulation and model. This might serve as a source to better understand the pattern - Six Sigma is inextricably connected with process (it is a process optimization tool) and Simulation is one of Industry 4.0 technologies.

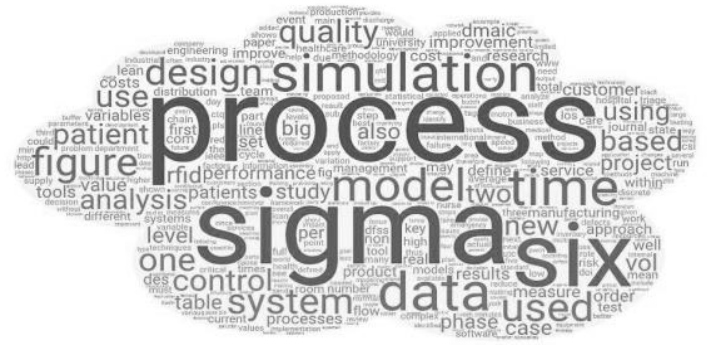

Figure 3. Word Cloud

Following the construction of the word cloud the analysis of key words and their connection was performed using the VOSviewer 1.6.16 application for bibliometric analysis. A map was constructed for the key words that appeared 4 or more times. As it could be seen in Figure 4,
10 major key words and phrases were found. Six Sigma is the most widespread followed by work simplification, simulation, discrete event simulation and computer simulation. Thus, the most important words in this study were identified as Six Sigma and Simulation.

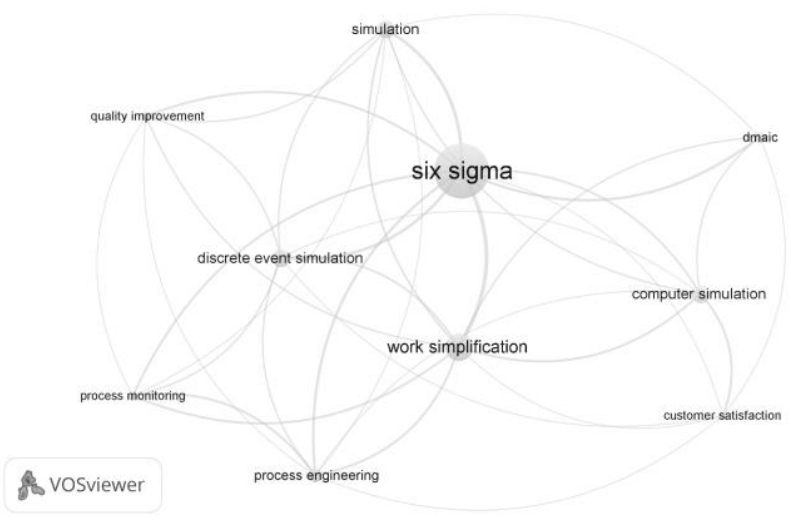

Figure 4. Key words Co-occurrence

The author analysis depicted in Figure 5 demonstrates that there are not many authors that have published more than 2 papers, namely Abdallah A. A. (the only author with 3 publications), Alfarah Y. M., Al-Shihabi S., Ferrin D. M., Kumar S., Mahanti R., Miller M. J., Mandahawi N. That could be explained by the fact that the amount of case studies is big (69\%) and authors deal with the only projects where they are trying to combine Six Sigma tools with Industry 4.0 technologies. Those projects might be further continued in the organizations, however no revisions on the similar organization were found.

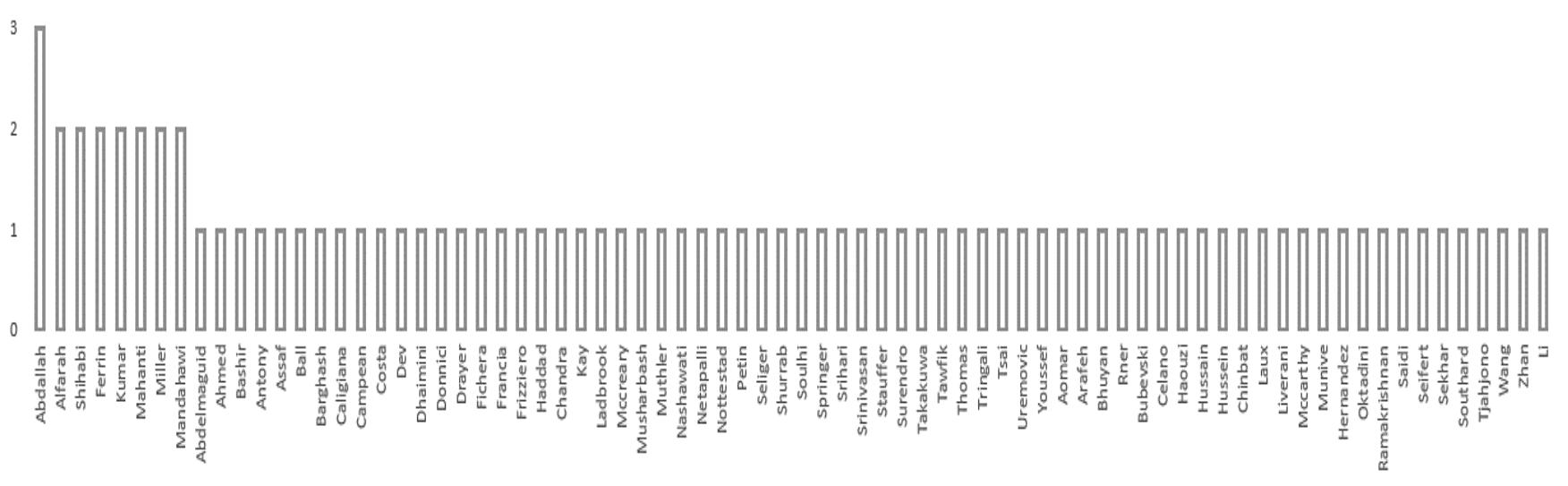

Figure 5. Published Articles by Author 
As the part of the author analysis the cooperation between authors was analyzed using the application VOSviewer 1.6.16. And it was found that not much of a cooperation could be seen. The authors are divided into several groups working on separate projects. However, the field is connected with advanced technologies there are no common patterns for communication between authors. Even within the similar technology (i.e. simulation) the cooperation between authors although exist doesn't create any cooperation between teams in the scopes of Six Sigma and advanced technology.

Another step of the research is to understand if the amount of citations is influenced by the year of the publication. For this purpose, a correlation analysis was made. The amount of citations was taken from Scopus web page; thus, it depicts how many times the work was cited in Scopus. As the number of correlations for different articles was from 0 (no citations) to 46 citation, the influence of the year on the citations was analyzed via correlation analysis. The $\mathrm{p}$-value was counted to be P-value was counted to be $P=2.96$, that means that the influence of the year cannot be proved. It is also proved by the fact that the most cited articles were published in the years 2012 (46 citations), 2005 (39 citations), 2010 (28 citations) and 2012 (27 citations).

At the last step of the bibliometric research part it was found that different Six Sigma tools were connected with different Industry 4.0 technologies. In Table 2 the number of conjunctions of DMAIC/DMADV and particular Industry 4.0 technologies is presented.

The Number of Conjunction of DMAIC/DMADV and Industry 4.0 Technologies

\begin{tabular}{|l|c|c|c|c|c|c|c|}
\hline & CPS & IIoT & Simulation & Robotics & Big Data & $\begin{array}{c}\text { Cloud } \\
\text { Computing }\end{array}$ & $\begin{array}{c}\text { Additive } \\
\text { manufact. }\end{array}$ \\
\hline DMAIC & & & 18 & & 2 & 1 & \\
\hline DMADV & & & 11 & & & & 1 \\
\hline
\end{tabular}

Thus, it could be said that the most important technology in the confluence of Six Sigma and Industry 4.0 is Simulation, as other technologies that were not studied were studied slightly. The amount of published papers is not big, and it is difficult to choose leaders in authors for this topic. The conjunction is concentrated on the processes, data, time, and other notions typical for both Six Sigma and Industry 4.0.

\section{Six Sigma and Industry 4.0 Technologies}

As the amount of papers on the conjunction is law, the conjunction of Six Sigma methodology with separate tools of Industry 4.0 was analyzed.

\section{Six Sigma and Simulation}

The majority of articles are dealing with the confluence of Six Sigma and Simulation. The given conjunction might be beneficial to provide better data for analysis of current situations, to be able to choose between alternatives, to diminish risks connected with introduction of new technologies etc. (Ahmed \& Page \& Olsen, 2020). Simulation might be used at all the stages of DMAIC (Ahmed, Page \& Olsen, 2020), (Chinbat \& Takakuwa, 2008) and DMADV (Chinbat \& Takakuwa, 2008) as it helps to identify better option in the given situation and/or to develop Six Sigma project (Celano, Costa, Fichera \& Tringali, 2012). Simulation can improve the analytics of Six Sigma (Ferrin \& Muthler, 2002), (Yachao, 2008), as the reduction of non-necessary variation can be done faster and with less costs. One paper-based simulation or role play was studied in order to investigate the influence of motivation of employees and top management and to provide the participants with tools necessary in practice (Borner \& Uremovic, 2010).
Several authors have analyzed the practical application of simulation for Six Sigma processes and found the conjunction to be effective from the point of view of reducing costs and time (Zhan, 2008; Chinbat \& Takakuwa, 2008; Seifert, 2005). Thus, an approach was proposed where simulation was integrated into Six Sigma DMAIC successfully (Al-Aomar \& Youssef, 2006), (El Haouzi, Petin \& Thomas, 2009). This might serve as supportive evidence of the fact that Simulation improves Six Sigma in the way of costs reduction. Abdallah also proposes to combine Six Sigma not only with Simulation but also with axiomatic design. He performs practical research in logistics and finds positive results of this combination (Abdallah, 2020). Another practical application was in Simulation and Six Sigma for design of assembly line and mini guide for process engineers was developed (Tjahjono, Ball, Ladbrook $\&$ Kay, 2009). Hussain et al. (Hussain, Campean \& MuniveHernandez, 2019) have also introduced a Discrete Event Simulation model for Six Sigma manufacturing processes. iGrafx Process Simulation was studied to be used by Black Belt (McCarthy, \& Stauffer, 2001) in their work and confirmed its convenience and appropriateness for specialists.

Simulation was also found to be favorable in combination with Six Sigma in Software development (Bubevski, 2010), as it helps to reduce costs, discard defects and advance reliability (Mahanti \& Antony, 2005). Another application of Six Sigma DFSS was found to be for server manufacturing, as this manufacturing a complex process, the conjunction with Six Sigma was favorable (Ramakrishnan, Tsai, Drayer \& Srihari, 2008). That combination might be of great use in the technological era. Another field of improvement of the combination was found to be in the environmental projects, that also present a huge contemporary interest (Sekhar \& Mahanti, 2006). 
Operational process Simulation was found to be effective in mining Six Sigma Projects (Chinbat \& Takakuwa, 2008) and process improvement.

Attention was also given to the usage of Simulation and Six Sigma in healthcare. Thus, two case studies in the emergency department were presented where Six Sigma and Simulation are connected and Simulation models are developed dealing successfully with overcrowding (Hussein, Abdelmaguid, Tawfik \& Ahmed, 2017), and improving processes time (Mandahawi, Shurrab, AlShihabi, Abdallah \& Alfarah, 2017). Similar case study was performed to reduce patient discharge time in cancer centers (Arafeh et al., 2018) that also proved the effectiveness of the combination of Simulation and Six Sigma in healthcare. Another case study considered the waiting time in emergency departments (Mandahawi, Shihabi, Abdallah \& Alfarah, 2010) where the process was improved considering the Voice of Customer. The usefulness of RFID for outpatient surgery was analyzed, using Six Sigma DMAIC process together with Simulation and it was found that RFID can improve the existing process (Southard, Chandra \& Kumar, 2012). Not only Six Sigma fits Simulation, but also Simulation techniques might fit an already existing Six Sigma structure in hospitals, as it can help to measure financial, operational indicators and customer satisfaction (Miller \& Ferrin, 2005).

Although the suitability of Six Sigma for complex processes is questioned (Palaci-Lopez, Borras-Ferris, da Silva de Oliveria \& Ferrer, 2020), (Saidi \& Soulhi, 2018) form the point of view of the suitability of traditional Six Sigma methods to the environment with abandoned data, a model was proposed on the basis of Simulation for Six Sigma projects that could be used in advanced industrial processes (El Haouzi, Petin \& Thomas, 2009). Another solution may be the adding of principal component analysis and partial least squares regression into Six Sigma methodology (Palaci-Lopez, Borras-Ferris, da Silva de Oliveria \& Ferrer, 2020).

Above benefits of Simulation for Six Sigma that were already discussed, some authors also used Six Sigma methods to improve the simulation techniques. In a practical study, it was found that the simulation parameters could be improved with DFSS (Bhuyan \& Netapalli \& Dev \& Srinivasan, 2015).

DMAIC in general helps to identify the priorities for the simulation process, thus making the simulation more productive and appropriate. Combining Six Sigma with Simulation was found to be profitable in healthcare, logistics (Kumar \& McCreary, \& Nottestad, 2011), software development, environmental projects and other industrial processes. This conjunction is the most auspicious nowadays from combinations of Six Sigma and Industry 4.0 technologies.

\section{Six Sigma and IIoT}

Although the Internet of Things is also connected with process optimization, no information on its practical application was found. The Internet of things being a technology that connects computers and industrial processes could also be a benefit for Six Sigma methodology and separate tools as it could improve data gathering processes and process stability.

\section{Six Sigma and Robotics}

In case of work several articles were found considering Six Sigma for Robotic arm (Szabo \& Gontean, 2017), however they were not taken for the final choice of articles as they were seeing Robotic arm modelling via Six Sigma cycles without assessing the connection of Six Sigma with Robotics. At the same time, it should be noted that as Six Sigma was already used in robotics projects it might be interesting from the point of view of its deeper integration. Six Sigma DMADV might be beneficial from the point of view of analysis of the technology to be implemented.

\section{Six Sigma and Big Data}

Big Data poses a big potential to be used to improve Six Sigma methodology (Antony, Gupta, Sunder \& Gijo, 2018), (Koppel \& Chang, 2020), as Six Sigma uses data for analytical purposes and the amount of data is growing. According to Koppel \& Chang (Koppel \& Chang, 2020) "the opportunities provided by Big Data environments would be of natural fit". Big Data could improve the autonomy of processes, as the data gathered in the process would be processed faster. Thus, the search for the problems in the process would be optimized by automation (Koppel $\&$ Chang, 2020). Moreover, a new approach called MDAIC instead of DMAIC was proposed, that implements data gathering prior to the Define stage, as the amount of data is growing, while its processing is becoming faster (Koppel \& Chang, 2020).

At the same time Big Data could benefit from Six Sigma. As Six Sigma is standardized method, it could improve some of Big Data characteristics such as "ignoring data quality, lack of a process approach, human context and minimizing data" (Laux, Li, Seliger \& Springer, 2017). Thus, the combination of Six Sigma and Big Data was found to be mutually beneficial.

\section{Six Sigma and Cloud Computing}

Six Sigma and Service Level Agreement for Cloud Computing were analyzed by (Oktadini, \& Surendro, 2014) and it was found that Six Sigma might be beneficial for IT infrastructure Library. Considering that Cloud Computing is also a complicated process, Six Sigma might be used to better understand and analyze the process with the purpose to avoid mistakes i.e. wastes.

\section{Six Sigma and Additive Manufacturing}

DMADV was used for Design for Additive Manufacturing as the way to avoid wastes and improve the process design (Liverani et al., 2019). As the usage of DFSS was positive in the paper, the further usage of Six Sigma methods for Additive Manufacturing might be profitable. Moreover, Additive Manufacturing is connected with design in its process, thus DFSS serve as a promising tool in these circumstances.

\section{Six Sigma and CPS}

Another technology that has not yet been discussed in the context of confluence with Six Sigma in Cyber-Physical System. Although it has not yet been mentioned, the usage of Six Sigma might bring some benefits especially at the stage of planning of CPS and analysis of its work. Those 
technologies could be used independently or together with other technologies such as simulation and/or Big Data with the purpose of creating optimal CPS in a company.

\section{Six Sigma and Machine Learning}

Although Machine Learning was not defined as an Industry 4.0 technology prior in the text, it is inevitably linked with technology and technological development. Thus, it is important to note that Saidi \& Soulhi (Saidi \& Soulhi, 2018) has argued in their paper that Six Sigma's tools should be better adapted to the complexity and might benefit from machine learning, especially DMAIC (Saidi \& Soulhi, 2018). As DMAIC represents a cycle, machine learning is reasonable to be used in connection with it, moreover it could be beneficial from both sides - the DMAIC cycle and Machine Learning implementation to the production.

Considering the preceding analysis, it can be seen that today the successful conjunction of Six Sigma has already been proved with some of the technologies of Industry 4.0. Thus, the engineer model for success in the complex environment of Industry 4.0 era should include Simulation for both DMAIC and DMADV, might include Big Data and Cloud Computing for DMAIC and Additive Manufacture for DFSS. Other technologies have not yet been analyzed and their integration with Six Sigma might be risky, however profitable.

\section{Discussion}

The conjunction of Six Sigma and Industry 4.0 tools have positive relationships, especially from the point of view of improving Six Sigma methodology to better answer the complexity needs. The combination of Six Sigma and Industry 4.0 technologies was found to be profitable for both Six Sigma methodology amelioration and Industry 4.0 introduction (Ferrin a Muthler, 2002), (Arafeh et al., 2018), (Miller a Ferrin, 2005). However, it was also found that the amount of published works in this direction is not big nor is sufficient. Separate technologies typical for Industry 4.0 were more analyzed (Simulation) while some technologies have not yet been analyzed in scientific papers (CPS, IIoT).

The bibliometric analysis proved the idea that the research on Six Sigma and Industry 4.0 is in its infancy and further research is needed to identify the pattern for research activities.

Although the positive relationship was witnessed by several authors the amount of work, considering this relationship is not sufficient. The further analysis of the following topics might be profitable to enrich Six Sigma methodology and implement Industry 4.0 tools. The major idea of the conjunction could be divided into parts: first, the influence of Six Sigma on Industry 4.0 technologies from the point of view of the necessity of Six Sigma methodology for the introduction of Industry 4.0 technologies to the company and further usage. Second, is the implementation of Industry 4.0 technologies for Six Sigma methodology to improve speed and cost of the processes. While the general understanding of the mutual influence of Six Sigma and Industry 4.0 is one of the most important topics that is in its infancy and needs further development, the mutual influence of separate technologies and tools that might be also considered are proposed further.
The usage of Industry 4.0 tools to improve the suitability of Six Sigma to the complex environment. In the case of research, two papers were found that stated a negative relation between Six Sigma and complexity (Saidi \& Soulhi, 2018), (Palaci-Lopez, Borras-Ferris, da Silva de Oliveria \& Ferrer, 2020). The usage of Industry 4.0 tools could change the situation as the advanced technologies allows the improved data gathering and data monitoring together with artificial intelligence and automatic learning that might benefit the usage of Six Sigma, the deeper studies of the Industry 4.0 influence might be needed.

The correlation between Big Data and Six Sigma and its practical application. Although Big Data is a promising tool for Six Sigma, only 3 papers were found dealing with this topic. However, Big Data might influence Six Sigma greatly as together with the improvement in data gathering and data analytics, the positive change in Six Sigma Measure and Analyze stages are inevitable.

The correlation between Lean Six Sigma and Industry 4.0. Although Lean Six Sigma was not considered in this article, the amount of the papers published on this topic todate is 3. Lean in Industry 4.0 was analyzed several times, although not as a part of Lean Six Sigma. As Lean Six Sigma is unavoidably connected with contemporary technologies as from the point of view of Lean (Lean automatics) as from the point of view of Six Sigma (especially data gathering, simulation and data storage), the studies of the impact of Industry 4.0 on Lean Six Sigma might increase the profitability of the implementation and usage of the methodology.

The development of the accepted synergy of Simulation and Six Sigma. Simulation was proved to be very efficient to be used in Six Sigma, thus a developed model combining both could be beneficial. This could be developed form both theoretical and practical perspectives, as the implementation of the real model in different backgrounds might be as interested as the development of theoretical model that could be later implemented and improved.

Six Sigma and Software development using Industry 4.0 tools. As only Simulation was found to be analyzed in one paper, but the potential of technologies and their development is great, this topic might be of great interest to be further developed. Moreover, as Six Sigma methodology cold be used in software development to optimize costs, the implementation of technologies that would improve the data gathering processes, simulation and storage might provide great benefit as for software companies these technologies are known and understandable.

Combination of Six Sigma and Simulation for process design. As several authors proved that the field has big potential further practical applications might be interesting. Simulation is the most promising tool for DFSS as it allows to try the proposed model without the interruption in the main business. The more structured approach for different companies, fields, company sizes and other parameters would provide practitioners with necessary information for their company.

The usage of Six Sigma tools for Additive Manufacturing, especially from the point of view of design (DFSS). As DFSS is connected with the preparation of the product for manufacturing, Additive Manufacturing may serve as an advantage for prototyping and searching for 
possible flows of the process. Together with Simulation it might provide an advanced system for Six Sigma and improve Six Sigma considerably as the new process preparation and amelioration according to the requirements would take less time and cost.

The application of Six Sigma tools for Cloud Computing services analysis might be better studied in the closest future. Only one paper was found dealing with cloud computing and proving that the confluence of Six Sigma and Cloud Computing is successful. Further research is needed to understand the confluence better. Here, the conjunction is beneficial, as on the one hand, the usage of Six Sigma for Cloud Computing processes might improve the Cloud System; on the other hand, the usage of Cloud Computing for Six Sigma purposes might provide the availability od data when and where it is required, thus reducing the necessary time for Six Sigma projects purposes.

The analysis of the possibility of connection of Six Sigma with IIoT and/or CPS, as this field has not yet been analyzed. From Industry 4.0 point of view, IIoT and CPS are the most interesting technologies as they contribute greatly to the change of the environment. At the same time, the influence of these technologies on Six Sigma has not yet been studied thoroughly. Considering the fact that Six Sigma methodology's success depends on data and IIoT and CPS provide changes in data collection, their conjunction might change the existing Six Sigma methodology greatly.

The proposed list for further research is not exhaustive, as the conjunction of Six Sigma and Industry 4.0 has not been thoroughly analyzed by different authors. Further development of these topics' analysis will bring better understanding of the conjunction and new topics for discussion might emerge.

The topics proposed prior and the general development of the conjunction of Six Sigma and Industry 4.0 technologies will be further monitored and developed as the analysis was presented in this paper.

As several further research topics were proposed, the research might be further developed either by following the research directions proposed in the article or by gathering statistical data concerning the real impact of Industry 4.0 on Six Sigma methodology. The research might be deepened also by including Lean methodologies as part of Lean Six Sigma methodology and its confusion with Industry 4.0 technologies.

Considering the nature of Six Sigma methodology based on data collection, it is supposed that the influence of emerging technologies on the methodology might be greater than it has already been estimated. Especially the integration of Industry 4.0 technologies into all Six Sigma tools might be interesting as the spread of the technologies influence greatly data collection, measurement and analysis methods, methods that are used to improve processes and to monitor the results, including the simulated results that might be further used in the future. These ideas were also supported by the authors who performed the combination of Six Sigma and different Industry 4.0 technologies (Kumar, McCreary \& Nottestad, 2011), (Oktadini, \& Surendro, 2014), (Laux, Li, Seliger \& Springer, 2017).
The article provides the overview of the existing theoretical data based on literature review and bibliometric analysis of the data. The information gathered and presented in the article could serve as a theoretical and practical foundation for future scientific and research work aimed at establishing the influence of Industry 4.0 on Six Sigma or at defining the applicability of Six Sigma methodology for Industry 4.0 technology introduction and usage. In the article it was found that the confluence of Six Sigma and Industry 4.0 technologies provide a positive effect on processes and this confluence should be further developed.

The study's findings are useful insights for researchers and practitioners of Six Sigma methodology. The future development of Industry 4.0 technologies will lead to improvement of Six Sigma methodology and its better application in practice.

\section{Conclusions}

The aim of this paper was to investigate the conjunction of Industry 4.0 technologies with Six Sigma methodology in order to identify future research perspectives and provide the researchers and practitioners with information about the framework of the conjunction. The influence of Industry 4.0 is growing today, and as Six Sigma is considered to be interlinked with technologies, their combination is important. In the case of the research, it was found that the interest towards Six Sigma in combination with Industry 4.0 technologies is promising in the contemporary environment.

The bibliometric research provided data on the existing situation and trends connected with Six Sigma and Industry 4.0 technologies. It was found out that no clear research or scientific pattern exists today, as the cooperation between authors working on the topic is low, the amount of publications is stable, however, it is insignificant, there are no journals typical for the topic, nor there are connections between citation level and year of publication. Thus, the research in this direction needs further investigation.

Considering different technologies separately, it was found that the most popular Industry 4.0 technology in conjunction with Six Sigma in Simulation. Simulation has already been investigated in different fields (healthcare, software, environment, engineering) and has proved to be effective from different points of view. The combination of Six Sigma and Simulation reduces costs, improves the process and helps to predict and to analyze the situation. The implementation of Simulation into existing Six Sigma processes was also found to be beneficial. Thus, the conjunction of Six Sigma with Simulation is a mutually beneficial combination for both Six Sigma methodology and Simulation techniques.

Other Industry 4.0 technologies were either not investigated or were considered just in a few papers, so the real influence of their conjunction is difficult to predict. However, the papers analyzing different technologies found their usage to be profitable in connection with Six Sigma.

Thus, the specialist, considering the implementation of Six Sigma or Industry 4.0 technologies, should consider their combinations, especially the most effective (Simulation) conjunctions and the most promising (Big Data), as the contemporary technologies might sufficiently improve the existing Six Sigma methodology. 


\section{Acknowledgement}

The author is thankful to the Internal Grant Agency of Tomas Bata University in Zlin No. IGA/FaME/2020/009 "Optimalizace procesů a znalostni informacni systémy jako podpora podniku v Industry 4.0" for financial support to carry out research.

\section{References}

Abdallah, A. (2020). Axiomatic Six Sigma, A Simulation-Based Decision-Making Framework. Journal of Mechanical Engineering Research and Developments, 43(7), 119-136.

Ahmed, A., Page, J., \& Olsen, J. (2020). Enhancing Six Sigma methodology using simulation techniques. International Journal of Lean Six Sigma, 11(1), 211-232. https://doi.org/10.1108/IJLSS-03-2018-0033

Al-Aomar, R., \& Youssef, M. (2006). Achieving Six Sigma rating in a system simulation model. International Journal of Six Sigma and Competitive Advantage, 2(2). https://doi.org/10.1504/IJSSCA.2006.010109

Antony, J., Gupta, S., Sunder M., V., \& Gijo, E. (2018). Ten commandments of Lean Six Sigma: a practitioners' perspective. International Journal of Productivity and Performance Management, 67(6), 1033-1044. https://doi.org/10.1 108/IJPPM-07-2017-0170

Arafeh, M., Barghash, M., Haddad, N., Musharbash, N., Nashawati, D., Al-Bashir, A., \& Assaf, F. (2018). Using Six Sigma DMAIC Methodology and Discrete Event Simulation to Reduce Patient Discharge Time in King Hussein Cancer Center. Journal of Healthcare Engineering, 2018, 1-18. https://doi.org/10.1155/2018/3832151

Bhuyan, D., Netapalli, S., Dev, S., \& Srinivasan, S. (2015). Design For Six Sigma (DFSS) for Optimization of Stamping Simulation Parameters to Improve Springback Prediction. SAE Technical Paper, 2015(2015-01-0582), https://doi.org/10.4271/2015-01-0582

Borner, R., \& Uremovic, A. (2010). SPARKING EMPLOYEES' INTEREST IN SIX SIGMA - Transferring a Paper-based Simulation to a Workflow Management Application. In: Proceedings of the 2nd International Conference on Computer Supported Education: CSEDU. Valencia, Spain: SciTePress - Science and and Technology Publications. Retrieved from: http://www.scitepress.org/DigitalLibrary/Link.aspx?doi=10.5220/0002769902030210

Bubevski, V. (2010). An Application of Six Sigma and Simulation in Software Testing Risk Assessment. 2010 Third International Conference on Software Testing, Verification and Validation, $295-302$. https://doi.org/10.1109/ICST.2010.23

Celano, G., Costa, A., Fichera, S., \& Tringali, G. (2012). Linking Six Sigma to simulation: a new roadmap to improve the quality of patient care. International Journal of Health Care Quality Assurance, 25(4), $254-273$. https://doi.org/10.1108/09526861211221473

Chinbat, U., \& Takakuwa, S. (2008). Using Operation Process Simulation for a Six Sigma project of Mining and Iron Production Factory. 2008 Winter Simulation Conference, 2431-2438. https://doi.org/10.1109/WSC.2008.4736351

Chromjakova, F., Tucek, D., \& Bobak, R. (2017). Projektovani vyrobnich procesu pro Průmysl 4.0. Zlin: Univerzita Tomase Bati ve Zline.

El Haouzi, H., Petin, J., \& Thomas, A. (2009). Design and validation of a product-driven control system based on a six sigma methodology and discrete event simulation. Production Planning and Control, 20(6), 510-524. https://doi.org/10.1080/09537280902938589

Ferrin, D., \& Muthler, D. (2002). Six Sigma and simulation, so what's the correlation?. Proceedings of the Winter Simulation Conference, 1439-1443. https://doi.org/10.1109/WSC.2002.1166415

George, M. (2003). Lean Six Sigma for Service: How to Use Lean Speed and Six Sigma Quality to Improve Services and Transactions. (1). McGraw-Hill Education.

George, M. (2002). Lean Six Sigma: combining Six Sigma quality with lean speed. New York: McGraw-Hill.

Hussain, A., Campean, F., \& Munive-Hernandez, J. (2019). Developing a Discrete Event Simulation Methodology to support a Six Sigma Approach for Manufacturing Organization: Case study. In: Proceedings of the International Conference on Industrial Engineering and Operations Management. Pilsen, Czech Republic. Retrieved from: http://ieomsociety.org/pilsen2019/papers/195.pdf

Hussein, N., Abdelmaguid, T., Tawfik, B., \& Ahmed, N. (2017). Mitigating overcrowding in emergency departments using Six Sigma and simulation: A case study in Egypt. Operations Research for Health Care, 15, 1-12. https://doi.org/10.1016/j.orhc.2017.06.003

Koppel, S., \& Chang, S. (2020). MDAIC - a Six Sigma implementation strategy in big data environments. International Journal of Lean Six Sigma, ahead-of-print. https://doi.org/10.1108/IJLSS-12-2019-0123 
Kumar, S., McCreary, M., \& Nottestad, D. (2011). Quantifying Supply Chain Trade-Offs Using Six Sigma, Simulation, and Designed Experiments to Develop a Flexible Distribution Network. Quality Engineering, 23(2), 180-203. https://doi.org/10.1080/08982112.2010.529481

Laux, C., Li, N., Seliger, C., \& Springer, J. (2017). Impacting Big Data analytics in higher education through Six Sigma techniques. International Journal of Productivity and Performance Management, 66(5), 662-679. https://doi.org/10.1108/IJPPM-09-2016-0194

Leyh, C., Martin, S., \& Schaeffer, T. (2017). Industry 4.0 and Lean Production - A Matching Relationship? An analysis of selected Industry 4.0 models. In: Proceedings of the 2017 Federated Conference on Computer Science and Information Systems (FEDCSIS). New York: IEEE. https://doi.org/10.15439/2017F365

Liverani, A., Caligiana, G., Frizziero, L., Francia, D., Donnici, G., \& Dhaimini, K. (2019). Design for Six Sigma (DFSS) for additive manufacturing applied to an innovative multifunctional fan. International Journal on Interactive Design and Manufacturing (IJIDeM), 13(1), 309-330. https://doi.org/10.1007/s12008-019-00548-9

Mahanti, R., \& Antony, J. (2005). Confluence of six sigma, simulation and software development. Managerial Auditing Journal, 20(7), 739-762. https://doi.org/10.1108/02686900510611267

Mandahawi, N., Shihabi, S., Abdallah, A., \& Alfarah, Y. (2010). Reducing waiting time at an emergency department using design for Six Sigma and discrete event simulation. International Journal of Six Sigma and Competitive Advantage, 6(1/2). https://doi.org/10.1504/IJSSCA.2010.034858

Mandahawi, N., Shurrab, M., Al-Shihabi, S., Abdallah, A., \& Alfarah, Y. (2017). Utilizing six sigma to improve the processing time: a simulation study at an emergency department. Journal of Industrial and Production Engineering, 34(7), 495-503. https://doi.org/10.1080/21681015.2017.1367728

McCarthy, B., \& Stauffer, R. (2001). Enhancing Six Sigma through simulation with iGrafx Process for Six Sigma. In: Proceeding of the 2001 Winter Simulation Conference (Cat. No.01CH37304). IEEE. Retrieved from: http://ieeexplore.ieee.org/document/977440; https://doi.org/10.1109/WSC.2001.977440

Miller, M., \& Ferrin, D. (2005). The Application of Simulation Methodology in a Hospital's Six Sigma Project. Proceedings of the Winter Simulation Conference, 2005, 2016-2019. https://doi.org/10.1109/WSC.2005.1574482

Oktadini, N., \& Surendro, K. (2014). SLA in cloud computing: Improving SLA's life cycle applying six sigma. In: 2014 International Conference on Information Technology Systems and Innovation (ICITSI). IEEE. Retrieved from: https://ieeexplore.ieee.org/document/7048278; https://doi.org/10.1109/ICITSI.2014.7048278

Palaci-Lopez, D., Borras-Ferris, J., da Silva de Oliveria, L., \& Ferrer, A. (2020). Multivariate Six Sigma: A Case Study in Industry 4.0. Processes, 8(9). https://doi.org/10.3390/pr8091119

Polk, J. (2011). Lean Six Sigma, innovation, and the change acceleration process can work together. Physician Executive, $37(1), 38-42$.

Pyzdek, T. (2003). The Six SIGMA Handbook: A Complete Guide for Greenbelts, Blackbelts, and Managers at All Levels. McGraw-Hill Companies.

Ramakrishnan, S., Tsai, P., Drayer, C., \& Srihari, K. (2008). Using simulation with Design For Six Sigma in a server manufacturing environment. In: 2008 Winter Simulation Conference. IEEE. Retrieved from: https://ieeexplore.ieee.org/document/4736282; https://doi.org/10.1109/WSC.2008.4736282

Saidi, R., \& Soulhi, A. (2018). Applying six sigma in smart factory: Limits and problems. ARPN Journal of Engineering and Applied Sciences: Asian Research Publishing Network (ARPN), 13(20), pp. 8316-8325.

Salkin, C., Oner, M., Ustundag, A., \& Cevikcan, E. (2018). A Conceptual Framework for Industry 4.0. In: Industry 4.0: Managing The Digital Transformation. Cham: Springer International Publishing. Retrieved from: http://link.springer.com/10.1007/978-3-319-57870-5_1; https://doi.org/10.1007/978-3-319-57870-5_1

Seifert, M. (2005). The Use of Discrete Event Simulation in a Design for Six Sigma Project. In: Proceedings of the Winter Simulation Conference, 2005. IEEE. Retrieved from: http://ieeexplore.ieee.org/document/1574479; https://doi.org/10.1109/WSC.2005.1574479

Sekhar, H., \& Mahanti, R. (2006). Confluence of Six Sigma, simulation and environmental quality. Management of Environmental Quality: An International Journal, 17(2), 170-183. https://doi.org/10.1108/14777830610650483

Shahin, A. (2008). Design for Six Sigma (DFSS): lessons learned from world-class companies. International Journal of Six Sigma and Competitive Advantage, 4(1). https://doi.org/10.1504/IJSSCA.2008.018420

Sony, M. (2017). Industry 4.0 and lean management: a proposed integration model and research propositions. Production \& Manufacturing Research, 6(1), 416-432. https://doi.org/10.1080/21693277.2018.1540949

Southard, P., Chandra, C., \& Kumar, S. (2012). RFID in healthcare: a Six Sigma DMAIC and simulation case study. International Journal of Health Care Quality Assurance, 25(4), 291-321. https://doi.org/10.1108/095268612112 21491 
Stankalla, R., Chromjakova, F., \& Koval, O. (2019). A review of the Six Sigma belt system for manufacturing small and medium-sized enterprises. Quality Management Journal, 26(2), 100-117. https://doi.org/10.1080/10686967.2019.158 0119

Szabo, R., \& Gontean, A. (2017). Sun tracker robotic arm optical distance measuring algorithm evaluation using Six Sigma methods. In: Proceedings of International Conference on Environment and Electrical Engineering (EEEIC). IEEE. Retrieved from: http://ieeexplore.ieee.org/document/7977645; https://doi.org/10.1109/EEEIC.2017.7977645

Tjahjono, B., Ball, P., Ladbrook, J., \& Kay, J. (2009). Assembly line design principles using Six Sigma and simulation. Proceedings of the 2009 Winter Simulation Conference (WSC), 3066-3076. https://doi.org/10.1109/WSC. 2009.5429219

Yachao, W. (2008). Data Mining from Simulation of Six Sigma in Manufacturing Company. 2008 International Conference on Computer Science and Software Engineering, 423-426. https://doi.org/10.1109/CSSE.2008.1198

Yeen Gavin Lai, N., Hoong Wong, K., Halim, D., Lu, J., \& Siang Kang, H. (2019). Industry 4.0 Enhanced Lean Manufacturing. In: 2019 8th International Conference on Industrial Technology and Management (ICITM). Cambridge, United Kingdom, United Kingdom: IEEE. Retrieved from: https://ieeexplore.ieee.org/document/8710669; https://doi.org/10.1109/ICITM.2019.8710669

Zhan, W. (2008). A Six Sigma approach for the robust design of motor speed control using modelling and simulation. International Journal of Six Sigma and Competitive Advantage, 4(2). https://doi.org/10.1504/IJSSCA.2008.020277

Zhevnov, D. (2013). Innovation-driven development of business using lean and six sigma approaches to process optimization. Vestnik finansovogo universiteta: Mezhdisciplinarnyie Issledovania, 127-132.

\section{Authors' biographies}

Anastasia Efimova is currently a $\mathrm{PhD}$ student at the Department of Industrial Engineering and Information Systems at Tomas Bata University in Zlin. The field of interest and studies includes Lean Six Sigma, Process Optimization, and Industry 4.0 influence. Studied Innovative Entrepreneurship during master's studies at Tomsk Polytechnic University. She has experience with the usage of Lean technologies for food industry processes.

Petr Briš is Doc. Ing., CSc., graduated from the Faculty of Technology in Zlín, Brno University of Technology, studied Technology of Textile, Leather, Rubber and Plastic Materials specializing in enterprise economics. He obtained the title CSc. at Moscow Institute of Technology MTILP. He is a holder of the certificate of Quality Manager in compliance with CSN EN ISO/IEC 17 024. He works as a senior lecturer at the Department of Production Management - Industrial Engineering, Faculty of Management and Economics at Tomas Bata University in Zlín. He has experience in research projects in the field of industrial systems management and the pedagogical field.

Alexander Efimov has graduated in June, 2021 from Tomas Bata University in Zlin with an engineer's degree in Security Technologies, Systems and Management - Security Management. He graduated from Tomsk Polytechnic University with a master's degree in Computation Systems, Complexes, and Nets. The research interests include computational techniques, Big Data, programming, statistics.

The article has been reviewed.

Received in February 2021; accepted in October 2021.

This article is an Open Access article distributed under the terms and conditions of the Creative Commons Attribution 4.0 (CC BY 4.0) License (http://creativecommons.org/licenses/by/4.0/). 